\title{
Information and Digital Toolset in a Fight against Liberal Democracy and Values of Open Society
}

\author{
Vasyl Filipchuk \\ Ph.D. in Public Administration, Associate Professor, Taras Shevchenko National University \\ of Kyiv (Kyiv, Ukraine) \\ E-mail: v.filipchuk@icps.com.ua \\ https://orcid.org/0000-0002-7335-2256
}

Filipchuk, Vasyl (2019) Information and Digital Toolset in a Fight against Liberal Democracy and Values of Open Society. Ukrainian Policymaker, Volume 5, 34-43. https:// doi.org/10.29202/up/5/4

The paper analyses the information and digital toolset in a fight against liberal democracy and values of open society. The overall trend of the present world development is such that transition to the post-industrial society, with its inherent variety of interests and values of different social groups and organizations, impetuous development of information technologies, etc. leads to transformation of political institutes of democracy. In connection to this, modern democracy faces serious challenges. Demands to its efficiency and associated expectations have grown, while the ability of democratic states to solve development problems has not changed much.

Inversion of democracy is also related with globalization and striving for comprehensive security. The decline of people's trust in the institutes of modern democracy; permanent growth of expectations from the regulatory capabilities of politics against the background of minimization of the idea of responsibility; the growing role of mass media and new uncontrolled decision-making centers that enter a competition with democratically legitimized institutes lead to atomization of society, its transformation into a set of autonomous information communities, giving rise to the "democracy of minorities", on the one hand, and to a democratic global government, on the other. To survive, democracy needs continuous flexible adaptation to external and internal challenges, as a long-term project. Its future lies in change, rather than in the desire to preserve stability.

Keywords: digital threats, information challenges, democracy, conflict discourse, political cynicism, post-truth

Received: December 1, 2019; accepted: December 14, 2019

(C) Filipchuk, Vasyl, 2019 


\section{Introduction}

New studies in the field of the theory of complex number systems question the idea that the democratic form of rule belongs to the most stable ones. An international group of scholars led by Karoline Wiesner, comprised of mathematicians, psychologists, political scientists and philosophers, paid attention to two functions of complex social systems - feedback loops and stability - that can pour light on the decline of the democratic form of rule (Oberhaus, 2018). The researchers note that citizens of democracies become ever less confident in their institutes of governance. They get increasingly inclined to reject institutes and norms, central for democracy. They are increasingly attracted by alternative, even autocratic forms of rule. This point may be proven with the democracy index calculated by the non-governmental organization Freedom House on the basis of such parameters as freedom of election, speech and civil rights, and witnessing a significant backslide of democracy all over the world in the recent years. Such process take place in two-times more countries than those that saw an increase in democratic principles.

The above-mentioned study shows how closely feedback loops are related with the state of democratic institutes. For instance, there is a direct dependency between economic inequality and a viable democracy. Where inequality between the rich and the poor grows, as it happened in the result of the crisis of 2008, democracy suffers, too. The reason is that democracy presumes basic equality of influence, scholars believe, but when economic inequality grows, some institutes begin to overweigh others. Those who have more money can influence society stronger than others. This may result in repudiation of the democratic form of rule.

The erosion of democracy is influenced not only by economic factors. Scholars have found out that if the population has extremely polar opinions, it also destabilizes a viable democracy. Due to irreconcilable positions, autocratic leaders try to impose their point of view by all means, and tend to break the principles of democracy rather than let the opponent win.

The third reason for the backsliding of democracy noted by scholars is the dilution of social norms, currently taking place mainly under the influence of social media. Scholars elaborate that extreme views move into the mainstream when they are legitimized by actual or presumed majority endorsement. If an opinion, no matter how absurd it may be, is shared by at least a portion of billions of Facebook users, this creates an opportunity for the emergence of a false consensus effect around any fringe opinion, because the social signal is distorted by global interconnectivity.

Hence, digital threats to democracy are more than real, especially in the era of substantial growth of influence of social networks and media on society. In order to realize the scope and power of influence of information and digital technologies, one should first analyze the level of digitalization of the present-day world.

\section{Conflict discourse and political cynicism as tools to fight against democracy and open society values}

Political pluralism is a vital feature of liberal democracy. It is associated with the freedom of mass media, as well as the freedom to form and express an opinion. To form one's opinion, alternative sources of information are needed. Ideally, implementation of those principles of democracy enables citizens to influence the political agenda. Said principles were implemented in the conditions of "pre-Internet", "pre-network" political communication. Political 
communication in the Internet differs by the subjects, style of presentation (usually, informal and impulsive), and the range of participants (ranging from politicians and experts to rank-andfile citizens). The traditional roles of a communicator (sender of information) and an addressee (recipient of information) are diluted. Under the influence of Internet forums and blogs, political communication is being personalized. However, this does not expand the freedom of opinions. First of all, Internet forums and blogs present kind of an "echo" to information delivered in the traditional media and by official communication channels (Wallsten, 2005). Second, using the terms of "generators of senses" and "consumers of senses", one can reveal "two layers" of political communication. "Generators of senses", engaged in social project planning, set a certain intellectual and emotional "interval", "corridor" for perception of information, ideas of its veracity or erroneousness, influence on the emotional perception of events. To create such "corridors", technologies of conflict discourse are used, since they make it possible to maintain political pluralism (true or imaginary).

The conflict discourse is ambivalent: 1) it is aimed at controversial interpretation of information; 2) it is manifested in the speaker's negative assessment of the addressee or the situation that arose in the result of his actions, with an intolerant, negativist, often aggressive style of communication. In the former case, the conflict discourse is associated with competitive assertion of claims to significance of presentation of information, being a sign of pluralism. The latter case goes with verbal aggression, insolence as a style of political behavior and its verbal justification.

The conflict discourse aimed at defamation of the opponent is based on unmasking, insults, verbal hits, derogatory term. The defamatory form of the conflict discourse associated with moral nihilism, breach of norms of communication and behavior, is manifested in political cynicism. Cynicism prompted by political mistakes, on the one hand, is manifested in largescale disappointment with the usefulness of the practices of governance, and on the other hand, in generators of senses' adherence to demagogic stock phrases, such as "national interests", "patriotism", "historic roots", simultaneously labelling objectors with negative stereotypes "fifth column", "traitors", etc.

Political cynicism of the elites is manifested in disdain to panhuman values, apology of the exceptionality of managerial functions and the need of separation of the ruling circles from the masses, self-confidence and refusal to accept criticism of the decisions taken. Manifestations of political cynicism include recruitment of administrative personnel on grounds of loyalty and personal devotion, resulting in opportunism and attempts to escape responsibility of executives at different levels. Political cynicism of the elites as abuse of power causes transformation of vertical pressure of the government on the population into different forms of horizontal pressure, intolerance and aggression, social apathy and atomization.

Political cynicism as an essential feature going with inefficient and disastrous political decisions and actions is manifested in the populist discourse and used to fight values of liberal democracy and open society. Antiliberal populists resort to technologies of praise of the addressee, the logic of similarity / community of positions and interests, intentional reductionism, simplification of problems while keeping silent about the real ways of their solution, the rhetoric of a unique road in spite of unfriendly partners / rivals. The logic of similarity disregards social differentiation, the need of a target policy while meeting public demands. By contrast to such a populist approach, the liberal pluralist discourse rests on the well-reasoned logic of differences and instrumental solutions to the problems. 
Therefore, the critical discourse, manifested in political cynicism, is widely used as an information and digital tool aimed at defamation of the opponent. This creates imaginary pluralism where logical arguments and rational practices of solution of social problems have no place, which bears a serious threat to modern democracy in the era of skyrocketing digitalization.

\section{Politicization of the Internet as a precondition to rule out "monopoly of power"}

The World Web and social networks are becoming an integral part of human life. As we mentioned, the Internet has provided a new platform for social relations, simplifying the process of communication among the people.

Many transitional political regimes try to strengthen control of the new media. The problem is that such systems require institutes not to promote democracy or social efficiency; their main task is to serve the interests of the rule-makers. In modern "educated" autocracies, mass media play the role of a certain "media army", providing information support for the political regime. Needless to say that such a mechanism works with utmost success, if the political agenda is controlled by the state.

There are several models of mass media impact on the audience: 1) transactional; 2) expectancy-value; 3) uses and dependency (Bryant \& Thompson, 2002: 149). The model of uses and dependence currently prevails in the majority of autocracies or electoral democracies. Such a mechanism is quite good for the government to use in so-called information cascades, where a piece of news is taken up and retransmitted by next to all mass media, producing an effect of greater reliability and better perception by the public. That is why the majority of the population in those countries are consumers of information, or what is called the truth by the official authorities.

Up to a point, the Internet and mass media played on different platforms. Politics was left to mass media, while the Internet more focused on entertainment and leisure. Understandably, politics was present there in the form of blogs, but they remained almost unnoticed in the general information discourse. The situation remained calm until large-scale politicization of the YouTube in 2011-2012. That platform harbored many channels that began to criticize the authorities; the "truth" of those channels rather strongly differed from that of the state, youths became politicized. This situation led to numerous youth protests against the governments (in Turkey, Iran, the Middle East, Latin America, South-East Asia, and Russia). Those events concurred with the development of portable electronic devices and high-speed mobile networks - 3G (followed by LTE), in closed-off countries (China, Iran, Tunisia, Syria) with mass adoption of VPN technologies. It is match harder to restrict undesired information in the web than in the traditional media.

The Internet turns into a new platform for the political life of the state. It provides the basis for political socialization, policy discussion, setting the agenda; it bears a huge potential for political mobilization of citizens. The Internet, by contrast to the traditional mass media, simplifies creation of new information channels, facilitates users' pooling on the basis of their political preferences, leading to emergence of great many independent news resources. Such resources include news web sites, blogs, groups in social networks, channels in messengers and personal pages of politicians in social networks. As a rule, each of those information platforms addresses its own, specific audience sharing the authors' opinion about social and 
political events, but this does not rule out the possibility of overlapping audiences of different new channels with a similar stand in the assessment of social problems.

In the conditions of presence of a large number of news resources, different ideological trends are fragmented. Adherents of different political views disagreeing with the existing political alliances may set up their own community and draw people with similar political views. However, such alliances do not retire into their shell and maintain communication with other communities - they share links to other groups, comment on posts, which leads to formation of a communication network of users, resting on horizontal ties. The situation as it has developed has a positive effect on the freedom of speech and pluralism of opinion, but at the same time, it bears negative effects, too.

Complication of the structure of modern society entails accumulation of social problems. Problems that are on the agenda of society are inevitably reflected in election programs and statements of political leaders, since the latter are expected to solve such problems. Supposedly, the political scene should see struggle of arguments about the future of the state, the ways of solution of problems faced by society. However, in a fragmented ideological environment, with great many independent news channels of information, the ideas of the ways of problem solution also multiply. Every information channel may act as an independent elucidator of events in the country, with its own idea of its future. Political leaders must give society a solution to every important problem, while the number of interpretations of those problems rises sharply. In this context, one may rightfully doubt if society can be consolidated by rational argumentation alone.

In this context, a social problem arises as a circumstance or situation labelled as a problem by actors on public discourse platforms. That said, the importance of a problem is determined not by its impartial assessment but by its collective perception. Every public stage has its "throughput capacity"; out of the huge "population" of potential problems, only a small portion receives coverage. As a result, social problems permanently compete to appear on the agenda and to stay there as long as possible. However, different formulations of the same problem also compete. The attention of consumers of information is also limited. Representatives of different social groups, as a rule, recognize a specific range of social problems and demonstrate a specific level of "personal compassion".

Social problems presented more dramatically are more likely to appear on the agenda. Problems associated with "deep mythological subjects or widespread cultural accents" also have a competitive advantage. Due to the limited "throughput capacity" of public platforms and individual attention, actors try to make reports concise. To attract attention, a report should also be striking.

In the conditions of network organization of information resources, the possibility of consolidation of the public on the basis of rational arguments is limited. To win elections, politicians have to resort to recognizable symbols, widespread myths and human emotions, which leads to formation of a political culture of "post-truth".

To be sure, the Internet and information technologies strengthen personal freedom of citizens and, as a result, limit powers of the state. Uncontrolled spread of information in social networks, messengers and YouTube poses a direct threat to the state media's monopoly of truth and stability of the political regime. Many undemocratic regimes try to use the Internet to disseminate unliberal culture and associated values in order to diffuse the effects of politicization of the web. 


\section{Post-truth as a way of manipulation of public consciousness in the modern world}

In modern society, the notion of "post-truth" gets increasingly widespread. Post-truth as a way of emotional influence on the audience is ever more frequently used in mass media and in social networks. The Oxford Dictionary gives the following definition of post-truth: "Relating to or denoting circumstances in which objective facts are less influential in shaping public opinion than appeals to emotion and personal belief" (Oxford Dictionary, 2019). Post-truth is a tool for manipulation of publicopinion and consciousness. The current "era of post-truth" should be viewed exactly through manipulation. Our consciousness is subjected to continuous manipulation by a great number of tools, such as mass media, Internet, cinema, music, culture. Introducing certain trends into the cultural core, one can reformat the consciousness and fates of whole states and nations.

The mechanism of operation of post-truth is similar to the mechanisms of propaganda and manipulation. The main features of post-truth include:

1. Appeal to emotions and personal convictions of the audience (post-truth means news taking place in the viewer's perception of the world).

2. Intentional understatement of actual facts, or facts inconsistent with the predetermined concept, with a focus only on the relevant portion of information, while the rest is just concealed.

3. Information overload, transmission of an endless stream of stories mainly consisting of abstract reflections.

4. Combinations of truth and lies.

5. Appearance of information at the "right" time, i.e., when most needed.

6. Provocation of a stormy reaction of the audience by imparting a "sensational" semantic charge to post-truth.

In the conditions of information society development, the role of mass media grows, as they give access to varied information for the wide public. At that, generators of information reports, using different media technologies, can influence the perception of one or another political event. The traditional tools of mass media influence on the audience, including construction of post-truth, are deemed to include media agenda setting, priming, and framing. Let us consider them in more detail.

The theory of media agenda setting proceeds from the idea of existence of a strong correlation between the emphasis made by mass media on a specific event and the significance attached to that event by the audience. Public awareness of different issues influences problem definition and rating. Mass media immediately influence public awareness (McCombs \& Shaw, 1972: 179). The perception of the importance of a specific subject for the public comes to the audience from mass media, in particular, dependent on the amount of data on the subject delivered to the public by the media (Kiousis \& McCombs, 2003: 146).

Priming is another technology of influence on mass consciousness. The basis of the huge potential influence of priming rests on the prime as an object, an encounter with which changes the ability of a person to deal with an identical or similar object. In substance, priming is a device contributing to prompt solution of any task and formation of an opinion on any problem thanks to similar questions or actions that took place in the past. 
Yet another tool of mass media influence on the audience is presented by framing. The theory of framing rests on the assumption that the audience will see the problem differently, dependent on how it is covered or interpreted in mass media. For instance, the same event may be presented as an act of violence or a tragic accident.

Therefore, a report transmitted in mass media strongly influences the public opinion. One cannot entirely change the opinion of a person using transmitted reports alone but can shape the recipient's opinion through selection of information and the method of its presentation.

In addition to the traditional tools of mass media influence on the audience, one should consider new media technologies of construction and dissemination of post-truth:

1. Personification of politics (the person of a political leader becomes more important than his ideas).

2. Emotionalization of politics (impetuous development of the Internet contributes to the shift of the audience's focus to emotions and feelings).

3. Entertaining politics (simplification and idealization of complex subjects along with funny presentation of information lead to the emotional perception of politics in general).

Mass media often resort to subjective coverage of events, being not only the original source but also the only channel of political information for the audience. For instance, viral media content in social networks, such as Facebook or Twitter, is the main source of political information for many citizens. Due to blanket distribution of information, it is deemed to be true, and the confidence in the content increases, disregarding however the likeliness of generation and circulation of disinformation (so-called "fake news").

In the "era of post-truth", it is similarly important to create new heroes or to glorify forgotten ones in the cinema or literature, no matter how real they are; those heroes can even be imaginary. The distinction between reality and fiction in post-truth becomes increasingly diluted. Modern society sees competition of discourses, and people's identity depends on discursive processes. It is the government that generates the people's identity and perception of one another, i.e., a person becomes a part of the discourse. Meanwhile, social groups with a non-dominant identity become "alien", which gives rise to social antagonisms.

Social antagonisms are widely covered in media reports using propaganda methods. One of the most common devices at coverage of military conflicts or protest campaigns is presented by the method of "creation of a threat image" (Pocheptsov, 2002: 170). This method is used mainly to strengthen and support the existing political regime and to demonize political opponents and the opposition, presenting them as criminal elements, provocateurs, killers. As a rule, such stories rest on the emotional component, where the target audience, viewers are so indignant with the creepy stories that they do not want any meaty evidence. It does not matter how veracious a story is, if it reflects the world perception of the target audience. Emotional manipulation is the main element of the "era of post-truth."

Post-truth originated from so-called information warfare and manipulation of consciousness. Methods of generation and dissemination of "fake news", employment of so-called "trolls" and "bots" engaged to disseminate specific information do influence the audience. In modern societies, post-truth as a tool of influence on the mass audience gains ground due to the growing popularity of social networks and the Internet. The Internet lets every user be a journalist, but lacks the "responsible editor". Exactly this gives rise to the large quantities of untrue information. 
The "society of post-truth" sprang up because, first of all, liberal democracy has entered the phase where "red lines" became widened and diluted; second, information technologies and social networks have reached such a level that individuals and small groups can exert political influence through them; third, a hedonistic mass information society has been formed, enchanted with populism, savoring sensations and preferring peace of mind and simple solutions. As a result, mechanisms of information networking began to set the paradigm of manipulation of mass consciousness in general, with the freedom of choice and self-actualization locked in a narrow corridor of distorted political reality, uneasy to go beyond.

\section{Conclusions}

Modern democracy and values of open society suffer ever heavier blows in many countries. Developed democracies are no exception. A tide of antidemocratic movements is on the rise in the USA, Germany, France, Italy, etc. Those movements acquire especially threatening features in East European countries - Hungary, Poland, Ukraine. In those countries, populists appealing to the theory of conspiracy try to put all the blame on liberal democrats, allegedly sucking rank-and-file citizens dry and enforcing tough reforms that do not give people a normal life and social peace in the end result. At the same time, the character of citizens' relations with traditional press undergoes qualitative changes: traditional mass media increasingly cede ground to social media providing a nutritional medium for the phenomenon of "post-truth" that, along with the conflict discourse, political cynicism, fakes and soft propaganda, turns into an information weapon against democracy and open society values.

Representatives of any part of the political spectrum now use digital technologies to spread disinformation and step up polarization. Although fake news and hate speech are not new, the present digital era - even if not intentionally — has created a favorable environment for them. The potential of the new technologies for improvement of the human life is beyond doubt, but the risks they pose for democracy are becoming increasingly evident.

In this connection, four challenges may be singled out, now high on the agenda of defense of modern democracy and values of open society.

The first challenge is presented by the growing industry of interference in the election process. While some people study presidential elections in the USA in 2016 in order to learn to escape such interference, others analyze that election campaign to improve election manipulation skills. Commercial consulting teams now tempt potential clients with ideas, how to efficiently influence elections using social networks, fake news and micro targeting. Can one overestimate the current threat to the global democracy, if election results can be influenced even in a mighty and technologically advanced country such as the USA?

The second challenge that gains strength is presented by the growing popularity of "home aids". Internet information monopolists already can determine, what the majority of the population of any country watches and what it believes in. As soon as such home aids as Google Home, Alexa and Siri become common, users will soon get not a range of option but one and only answer to their inquiries. Such hyper care will inevitably reduce our search activity, research potential and level of discussion, giving a few companies and algorithms even more powers to polish our knowledge and convictions.

The third threat lies in the emergence of fake video materials - so-called deep fakes. This method, employing artificial intelligence and synthesis of images, makes it possible to create a video that cannot be distinguished from an original footage. Imagine, for instance, the speed of 
spread of a fake video recording of the Iranian president ordering his generals to prepare for an armed invasion in Israel in the Internet. Growing popularity of deep fakes will inevitably lead to the decrease of the general confidence in the video content. As soon as the real and virtual worlds continue to merge together, we can lose the ability to distinguish, what is real in the democratic policy, and what is not.

The last but not least is the challenge of the P2P platform with an encryption mode. WhatsApp application, monthly used by over 1.5 billion active users in 180 countries, was employed to spread rumors and instigate violence in Brazil, Mexico and India — just as Facebook was used to foster violence between different communities in Sri Lanka, Myanmar and Bangladesh. Indeed, anonymity and encryption provided by WhatsApp are strong tools of defense of citizens fighting for their democratic rights under violent authoritarian regimes, but the same features complicate identification of real sources of rumors, hatred and instigation of violence, which, in turn, complicates investigation of WhatsApp use for manipulation of election results.

While we tend to see digital technologies as threats for the existing political systems, other people see in them new opportunities to influence the election results. Coping with and containment of those threats is to become a top priority for democracies in any place on earth.

To defend the values of open society and efficiently counter present day information and political challenges, it is necessary:

First of all, to use clear and correct notions, in particular, to distinguish a referendum from a plebiscite that has nothing in common with democratic voting or direct democracy. Democratically elected governments should maintain real and serious dialogue with citizens in-between elections, otherwise the rift between the people and its representatives will widen exponentially, which will be used by all kinds of populists to the full extent. This rift may be narrowed by direct democracy, especially the tool of the popular legislative initiative.

Second, direct democracy should in the first place rely on digital technologies, including for organization of mass political events and new capabilities of political project funding, for instance, by means of crowd-funding. Democratic governments should contact their citizens and ask them about their needs.

Third, creation of online platforms, on the one hand, providing educational space for adoption of political democracy and demonstrating the best practices of democratic governance, on the other - providing a platform for unification of liberal democrats, promotion of values of open society and joining efforts against populists. More room for discussion should be provided - so-called Massive Online Deliberation Platforms, enabling people to communicate in a different key than it happens in social networks now. This additional room should be subject to pre-moderation with strict rules, and more sophisticated systems relying on artificial intelligence technologies should be able to identify and cut off so-called "trolls", paid distributors of disinformation, seeking to turn any civilized discussion into a mess. Such "platforms for discussion", by the way, open for high-quality mass media, should also operate on the basis of special algorithms, but they will not contribute to heightening of emotions and retransmission of hatred but support reasonable arguments.

Fourth, to restore confidence in the electoral democracy through perfection of the election legislation in terms of the election system and raising responsibility for buying votes.

Fifth, to bring up the current youth, in order to instill values of open society, encourage critical thinking and give rise to a demand for ideological parties with institutional safeguards, keeping their representatives within the value-based frameworks of their ideological trend. 


\section{References}

Bryant, Jennings and Susan Thompson (2002) Fundamentals of Media Effects. McGraw-Hill Companies.

Kiousis, Spiro and Max McCombs (2003) Agenda setting effects and strength. MT Journal. Vol. 142, 145-150.

McCombs, Max and Donald Shaw (1972) The agenda-setting function of mass media. Public Opinion Quarterly, Volume 36, Issue 2, 176-187. https://doi.org/10.1086/267990

Oberhaus, Daniel (2018) Complex Systems Theorists Explain Why Democracy Is Dying. VICE. https://www.vice.com/en_us/article/mby3ja/complex-systems-theoristsexplain-why-democracy-is-dying

Oxford Dictionary (2019). https://en.oxforddictionaries.com/definition/post-truth

Pocheptsov, G. (2000) Communicative technologies of the twentieth century. Moscow:ReflBook, Vakler. (in Russian)

Wallsten, Kevin(2005) Political Blogs and the Bloggers Who Blog Them: Is the Political Blogosphere and Echo Chamber? https://pdfs.semanticscholar.org/5a53/2ca1175c49 4412781625fed25b372f51c408.pdf 